\title{
Website Analisa Gangguan Belajar pada Anak dengan Metode Dempster Shafer
}

\author{
Ardani Tanaka*, Yopi Hendro**, Risky Amanda** \\ Program Studi Informasi, STMIK Triguna Dharma
}

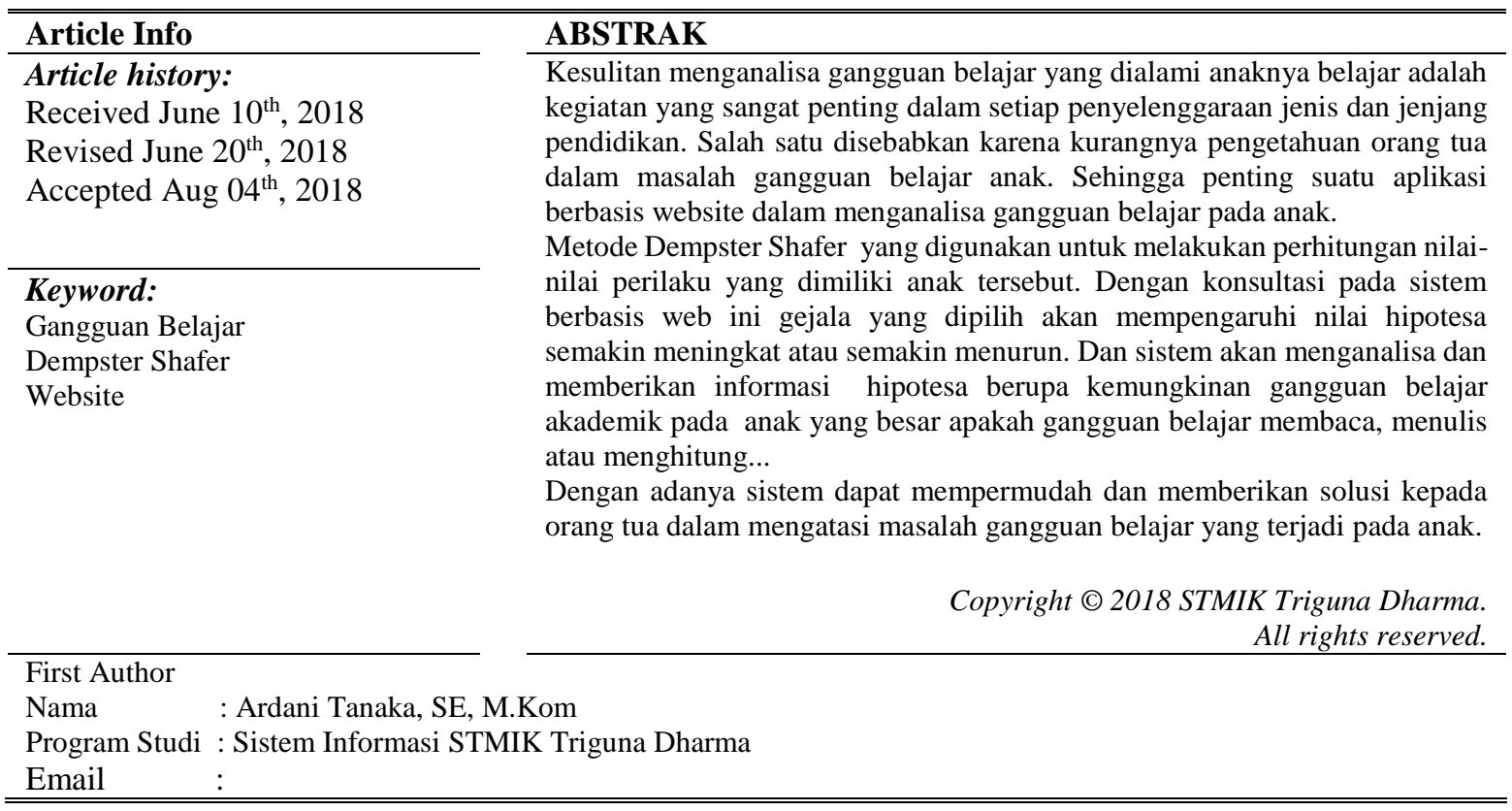

\section{PENDAHULUAN}

Pada masa sekarang ini banyak sekali orang tua yang sulit menganalisa gangguan belajar yang dialami anaknya, padahal belajar adalah kegiatan yang sangat penting dalam setiap penyelenggaraan jenis dan jenjang pendidikan. ini berarti bahwa berhasil atau gagalnya pencapaian tujuan pendidikan itu amat bergantung pada proses belajar yang dialami, baik ketika ia berada dalam sekolah maupun di lingkungan rumah atau keluarga sendiri, bahkan bukan anak-anak yang berkemampuan kurang saja, tetapi juga dialami oleh anak-anak yang berkemampuan tinggi. Selain itu, anak yang berkemampuan rata-rata juga mengalami gangguan dalam belajar. Sedangkan gangguan belajar itu merupakan kondisi proses belajar yang ditandai oleh hambatan-hambatan tertentu untuk mencapai kesuksesan. Maka untuk mempermudah orang tua menganalisa gangguan belajar akademik yang terjadi pada anak dibutuhkan suatu sistem yang dapat dijadikan sebagai pengganti pakar untuk berkonsultasi.Metode yang diterapkan dalam perhitungan metode Dempster Shafe yang bagian dari sistem pakar. Metode Dempster Shafer merupakan suatu teori matematika untuk pembuktian berdasarkan fungsi kepercayaan dan pemikiran yang masuk akal yang digunakan untuk mengkombinasikan potongan informasi terpisah untuk mengkalkulasikan kemungkinan dari suatu peristiwa .Berdasarkan latar belakang permasalahan di atas, maka perlu sebuah website untuk melakukan analisa gangguan belajar pada anak dan memberikan hasil yang konsisten, cepat dan tepat,serta memberikan solusi terhadap gangguan tersebut.

\section{LANDASAN TEORITIS}

\subsection{Dempster Shafer}

Metode Dempster Shafer adalah suatu teori matematika untuk pembuktian berdasarkan belief function ane plausible reasoning (fungsi kepercayaan dan pemikiran yang masuk akal Yng digunakan untuk mengkombinasikan potongan informasi yang terpisah (bukti) untuk mengkalkulasikan kemungkinan dari suatu peristiwa ( zulfian azmi.2017).

Metode pertama kali diperkenalkan oleh Dempster, yang melakukan percoban model ketidakpastian dengan range probabilitas sebagai probabilitas tunggal. Kemudian pada tahun 1976 Shafer mempublikasikan teori Dempster tersebut pada sebuah buku yang berjudul Mathematical Theory of Evident. Secara umum teori 
Dempster Shafer ditulis dalam suatu interval [Belief, Plausibility]. Belief (Bel) adalah ukuran kekuatan evidence dalam mendukung suatu himpunan proposisi. Jika bernilai 0 (nol) maka mengindikasikan bahwa tidak ada evidence, dan jika bernilai 1 menunjukkan adanya kepastian Menurut Giarratano dan Riley (dalam Minardi dan Suyanto, $2016: 85)$.

Secara umum formulasi untuk Dempster's Rule of Combination ditunjukkan dengan persamaan berikut:

Keterangan:

$$
\mathrm{m} 1 \oplus \mathrm{m} 2(\mathrm{Z})=\frac{\sum_{\mathrm{X} \cap \mathrm{Y}=\mathrm{Z}} \mathrm{m} 1(\mathrm{X}) \mathrm{m} 2(\mathrm{Y})}{1-\mathrm{k}}
$$

$\mathrm{k}$ : jumlah evidencial conflict

Besarnya jumlah evidencial conflict (k) dirumuskan dengan:

$$
\mathrm{k}=\sum_{\mathrm{X} \cap \mathrm{Y}=\varnothing} \mathrm{m} 1(\mathrm{Z}) \mathrm{m} 2(\mathrm{Y})
$$

\subsection{Gangguan Belajar}

Menurut Suryani (2010:39) gangguan belajar akademik terbagi atas 3 bagian yaitu :

1. Disleksia atau Gangguan Membaca

Disklesia atau gangguan membaca adalah kesulitan untuk memaknai symbol, huruf dan angka melalui persepsi visual dan auditoris. Hal ini akan berdampak pada kemampan pemahaman.

2. Disgrafia atau Gangguan Menulis

Disgrafia adalah kesulitan yang melibatkanproses menggambar simbol bunyimenjadi simbol huruf atau angka. Gangguamenulis tersebut terjadi pada beberapa tahap aktivitas menulis yaitu :mengeja, yaitu aktivitas memproduksi urutan huruf yang tepat dalam ucapan atau tulisan dari suku kata.

3. Diskalkulia atau Gangguan Berhitung

Gangguan berhitung adalah kesulitan menggunakan bahasa simbol untukberfikirberfikir,mencatat,dan mengkomunikasikan ide-ideyang berkaitan dengan kuantitas atau jumlah.Kemampuan berhitung sendiri terdiri dari kemampuan yang bertingkat dari kemampuan dasar sampai kemampuan lanjut.

\section{ANALISIS DAN HASIL}

Sumber pengetahuan dari seorang pakar yang akan dipindahkan kedalam sebuah sistem komputer terlebih dahulu harus dijadikan kesebuah tabel sebagai media penyimpanan dan pengetahuan yang nantinya akan menjadi sumber pengetahuan komputer. Sehingga tabel pengetahuan ini sangat menentukan proses perhitungan dan hasil diagnosa dalam menentukan jenis gangguan belajar akademik anak, yang kemudian akan diketahui cara penanggulangannya. Berikut merupakan tabel pengetahuan yang akan digunakan dalam menganalisa jenis gangguan belajar akademik anak :

Tabel 1 Jenis-Jenis Gangguan Belajar

\begin{tabular}{|c|c|l|}
\hline No & Kode Gangguan & \multicolumn{1}{|c|}{ Nama Gangguan } \\
\hline 1 & A & Disleksia (Gangguan Membaca ) \\
\hline 2 & B & Disgrafia ( Gangguan Menulis ) \\
\hline 3 & C & Diskalkulia (Gangguan Menghitung ) \\
\hline
\end{tabular}

Tabel 2 Perilaku Anak

\begin{tabular}{|c|c|l|}
\hline No & Kode Perilaku & \\
\hline 1 & P1 & Perilaku Anak \\
\hline 2 & P2 & Lamban dalam mempelajari nama dan bunyi abjad \\
\hline
\end{tabular}




\begin{tabular}{|c|c|c|}
\hline 3 & P3 & Kesulitan mengeja \\
\hline 4 & P4 & Lamban saat didikte atau menyalin tulisan \\
\hline 5 & P5 & Tidak jelas dalam berbicara \\
\hline 6 & P6 & Terdapat ketidak konsistenan bentuk huruf dalam tulisannya \\
\hline 7 & P7 & Saat menulis, huruf besar dan huruf kecil masih tercampur \\
\hline 8 & P8 & Sulit Berkonsentrasi \\
\hline 9 & P9 & $\begin{array}{l}\text { Anak tampak harus berusaha keras saat mengkomunikasikan suatu ide, } \\
\text { pengetahuan, atau pemahamannya lewat tulisan }\end{array}$ \\
\hline 10 & $\mathrm{P} 10$ & Sulit memegang bolpoin maupun pensil dengan mantap \\
\hline 11 & $\mathrm{P} 11$ & Menulis tidak mengikuti alur garis yang tepat dan proporsional \\
\hline 12 & P12 & $\begin{array}{l}\text { Tetap mengalami kesulitan meskipun hanya diminta menyalin contoh tulisan } \\
\text { yang sudah ada }\end{array}$ \\
\hline 13 & $\mathrm{P} 13$ & Sulit melakukan hitungan matematis. \\
\hline 14 & P14 & Sulit menulis angka berurutan \\
\hline 15 & P15 & Sulit menghitung transaksi (belanja), termasuk menghitung kembalian uang \\
\hline 16 & P16 & Bingung saat ditanya jam berapa sekarang \\
\hline 17 & $\mathrm{P} 17$ & Tidak mampu membaca dan memahami peta atau petunjuk arah \\
\hline 18 & P18 & Sulit Berimajinasi \\
\hline 19 & P19 & $\begin{array}{l}\text { Angka dan huruf sering tertukar misal huruf "d" sering tertukar dengan huruf "b", } \\
\text { atau angka " } 6 \text { " dengan angka " } 9 \text { " }\end{array}$ \\
\hline 20 & $\mathrm{P} 20$ & $\begin{array}{l}\text { Kurangnya pemahaman anak mengenai nilai tempat satuan, puluhan, ratusan dan } \\
\text { seterusnya }\end{array}$ \\
\hline 21 & $\mathrm{P} 21$ & $\begin{array}{l}\text { Mengalami hambatan dalam mempelajari musik, terutama karena sulit } \\
\text { memahami notasi, urutan nada }\end{array}$ \\
\hline
\end{tabular}


\begin{tabular}{l|l|l}
22 & P22 & $\begin{array}{l}\text { Mengalami kesulitan dalam aktivitas olahraga karena bingung mengikuti aturan } \\
\text { main yang berhubungan sistem skor }\end{array}$
\end{tabular}

Tabel 3 Basis Pengetahuan

\begin{tabular}{|c|c|c|c|c|}
\hline No & Kode Perilaku & A & B & $\mathrm{C}$ \\
\hline 1 & P1 & $\mathrm{P}$ & & \\
\hline 2 & $\mathrm{P} 2$ & $\mathrm{P}$ & $\mathrm{P}$ & \\
\hline 3 & P3 & $\mathrm{P}$ & & \\
\hline 4 & P4 & $\mathrm{P}$ & $\mathrm{P}$ & \\
\hline 5 & P5 & $\mathrm{P}$ & & \\
\hline 6 & P6 & & $\mathrm{P}$ & \\
\hline 7 & P7 & $\mathrm{P}$ & $\mathrm{P}$ & \\
\hline 8 & P8 & & $\mathrm{P}$ & $\mathrm{P}$ \\
\hline 9 & P9 & $\mathrm{P}$ & $\mathrm{P}$ & \\
\hline 10 & P10 & & $\mathrm{P}$ & \\
\hline 11 & P11 & & $\mathrm{P}$ & \\
\hline 12 & P12 & $\mathrm{P}$ & $\mathrm{P}$ & \\
\hline 13 & P13 & & & $\mathrm{P}$ \\
\hline 14 & P14 & & $\mathrm{P}$ & $\mathrm{P}$ \\
\hline 15 & P15 & & & $\mathrm{P}$ \\
\hline 16 & P16 & & & $\mathrm{P}$ \\
\hline 17 & P17 & $\mathrm{P}$ & & $\mathrm{P}$ \\
\hline 18 & P18 & & $\mathrm{P}$ & $\mathrm{P}$ \\
\hline 19 & P19 & $\mathrm{P}$ & $\mathrm{P}$ & $\mathrm{P}$ \\
\hline 20 & $\mathrm{P} 20$ & & & $\mathrm{P}$ \\
\hline 21 & $\mathrm{P} 21$ & $\mathrm{P}$ & & $\mathrm{P}$ \\
\hline 22 & $\mathrm{P} 22$ & & & $\mathrm{P}$ \\
\hline
\end{tabular}

Dalam penyelesaian menentukan jenis gangguan belajar yang tepat terhadap anak menggunakan sistem pakar berbasis rule (rule based system), yaitu pengetahuan disimpan dalam bentuk rule, sebagai prosedur pemecahan masalah . Berikut adalah representasi pengetahuan sistem pakar dalam menganalisa jenis gangguan belajar akademik anak :

\section{Rule 1}

: If Perilaku P1 AND P2 AND P3 AND P4 AND P5 AND P7 AND P9 AND P12 AND P16 AND P17 AND P21

Then Disleksia (gangguan membaca).

Rule 2

: If Perilaku P2 AND P4 AND P6 AND P7 AND P8 AND 
P9 AND P10 AND P11 AND P12 AND P14 AND P18 P19

Then Disgrafia (gangguan menulis).

Rule 3

: If Perilaku P8 AND P13 AND P14 AND P15 AND P16 AND

P17 AND P18 AND P19 AND P20 AND P21 AND P22

Then Diskalkulia (gangguan berhitung).

Berikut ini merupakan tabel nilai densitas dari perilaku-perilaku gangguan belajar akademik anak Tabel 4 Nilai Densitas Perilaku Anak

\begin{tabular}{|c|c|c|c|}
\hline No & Kode Perilaku & Perilaku Anak & Bobot \\
\hline 1 & P1 & Lamban dalam mempelajari nama dan bunyi abjad & 0.85 \\
\hline 2 & $\mathrm{P} 2$ & Lamban saat menulis dan tulisan yang tidak rapi & 0.70 \\
\hline 3 & P3 & Kesulitan mengeja & 0.85 \\
\hline 4 & P4 & Lamban saat didikte atau menyalin tulisan & 0.75 \\
\hline 5 & P5 & Tidak jelas dalam berbicara & 0.75 \\
\hline 6 & P6 & $\begin{array}{l}\text { Terdapat ketidak konsistenan bentuk huruf dalam } \\
\text { tulisannya }\end{array}$ & 0.75 \\
\hline 7 & P7 & $\begin{array}{l}\text { Saat menulis, Pasienan huruf besar dan huruf kecil masih } \\
\text { tercampur }\end{array}$ & 0.80 \\
\hline 8 & P8 & Sulit Berkonsentrasi & 0.75 \\
\hline 9 & P9 & $\begin{array}{l}\text { Anak tampak harus berusaha keras saat } \\
\text { mengkomunikasikan suatu ide, pengetahuan, atau } \\
\text { pemahamannya lewat tulisan }\end{array}$ & 0.80 \\
\hline 10 & $\mathrm{P} 10$ & Sulit memegang bolpoin maupun pensil dengan mantap & 0.85 \\
\hline 11 & P11 & $\begin{array}{l}\text { Menulis tidak mengikuti alur garis yang tepat dan } \\
\text { proporsional }\end{array}$ & 0.75 \\
\hline 12 & P12 & $\begin{array}{l}\text { Tetap mengalami kesulitan meskipun hanya diminta } \\
\text { menyalin contoh tulisan yang sudah ada }\end{array}$ & 0.70 \\
\hline 13 & $\mathrm{P} 13$ & Sulit melakukan hitungan matematis. & 0.75 \\
\hline 14 & P14 & Sulit menulis angka berurutan & 0.75 \\
\hline 15 & P15 & $\begin{array}{l}\text { Sulit menghitung transaksi (belanja), termasuk } \\
\text { menghitung kembalian uang }\end{array}$ & 0.75 \\
\hline
\end{tabular}




\begin{tabular}{|c|l|l|c|}
\hline 16 & P16 & Bingung saat ditanya jam berapa sekarang & 0.75 \\
\hline 17 & P17 & $\begin{array}{l}\text { Tidak mampu membaca dan memahami peta atau } \\
\text { petunjuk arah }\end{array}$ & 0.80 \\
\hline 18 & P18 & Sulit Berimajinasi & 0.85 \\
\hline 19 & P19 & $\begin{array}{l}\text { Angka dan huruf sering tertukar misal huruf "d" sering } \\
\text { tertukar dengan huruf "b", atau angka "6" dengan angka } \\
\text { "9" }\end{array}$ & 0.70 \\
\hline 21 & P20 & $\begin{array}{l}\text { Kurangnya pemahaman anak mengenai nilai tempat } \\
\text { satuan, puluhan, ratusan dan seterusnya }\end{array}$ & 0.80 \\
\hline 22 & P21 & $\begin{array}{l}\text { Mengalami hambatan dalam mempelajari musik, terutama } \\
\text { karena sulit memahami notasi, urutan nada }\end{array}$ & 0.75 \\
\hline
\end{tabular}

Jika seorang ibu ingin menganalisa gangguan belajar akademik anaknya. Kemudian ibu tersebut akan melakukan konsultasi dan menjawab beberapa pertanyaan yang berkaitan dengan perilaku anaknya. Berikut adalah jawaban-jawaban yang dipilih ibu tersebut :

Tabel 5 Jawaban Pertanyaan

\begin{tabular}{|c|c|l|}
\hline No & Kode & \\
\hline 1 & P1 & Lamban dalam mempelajari nama dan bunyi abjad \\
\hline 2 & P2 & Lamban saat menulis dan tulisan yang tidak rapi \\
\hline 3 & P3 & Kesulitan mengeja \\
\hline 4 & P4 & Lamban saat didikte atau menyalin tulisan \\
\hline 5 & P8 & Sulit Berkonsentrasi \\
\hline
\end{tabular}

Berikut adalah proses perhitungan metode Dempster Shafer untuk menganalisa gangguan belajar anak berdasarkan tabel diatas :

\section{Perilaku 1 : Lamban dalam mempelajari nama dan bunyi abjad (P1)}

Langkah pertama hitung nilai belief dan Plausability dari perilaku 1 (P1), yang merupakan analisa dari gangguan disleksia $(\mathrm{A})$ :

$\mathrm{m} 1(\mathrm{P} 1)=0.85$

$\mathrm{m} 1\{\theta\}=1-\mathrm{m} 1(\mathrm{P} 1)$

$$
=1-0.85=0.15
$$

\section{Perilaku 2 : Lamban saat menulis dan tulisan yang tidak rapi}

Kemudian apabila diketahui adanya perilaku baru, yaitu Lamban saat menulis dan tulisan yang tidak rapi (P2), yang merupakan diagnosa dari gangguan diskleksia (A) dan disgrafia (B), maka nilai keyakinannya adalah :

$\mathrm{m} 2(\mathrm{P} 2)=0.70$

$\mathrm{m} 2\{\theta\}=1-\mathrm{m} 1(\mathrm{P} 2)$

$=1-0.70=0.30$. Jika diilustrasikan dalam tabel : 


\begin{tabular}{|ll|ll|lc|}
\hline & M2\{A,B & 0.70 & \multicolumn{2}{|c|}{ M2 $(\theta)$} & 0.30 \\
\hline $\operatorname{m} 1\{\mathrm{~A}\}$ & 0.85 & $\{\mathrm{~A}\}$ & 0,595 & $\{\mathrm{~A}\}$ & 0,255 \\
\hline $\mathrm{M} 1(\theta)$ & 0.15 & $\{\mathrm{~A}, \mathrm{~B}\}$ & 0,105 & $(\theta)$ & 0,045 \\
\hline
\end{tabular}

$\mathrm{m} 3\{\mathrm{~A}\}=\frac{0.595+0,255}{1-0}=0,85$

$\begin{array}{lll}\mathrm{m} 3\{\mathrm{~A}, \mathrm{~B}\} & =\frac{0,105}{1-0} & =0,105 \\ \mathrm{~m} 3(\theta) & =\frac{0,045}{1-0} & =0,045\end{array}$

Nilai keyakinan paling kuat adalah terhadap gangguan disleksia (G1) yaitu sebesar 0.85. yang di dapatkan dari dua perilaku yaitu P1 dan P2.

\section{Perilaku 3 : Kesulitan mengeja}

Kemudian apabila diketahui adanya perilaku baru, yaitu kesulitan mengeja (P3) yang merupakan analisa dari gangguan disleksia $(\mathrm{A})$ :

$\mathrm{m} 4(\mathrm{P} 3)=0.85$

$\mathrm{m} 4\{\theta\}=1-\mathrm{m} 4(\mathrm{P} 2)$

$=1-0.85=0.15$. Jika diilustrasikan dalam tabel :

Tabel 7 Ilustrasi Nilai Keyakinan Tiga Gejala

\begin{tabular}{|c|c|c|c|c|c|}
\hline & & $\mathrm{m} 4$ & 0.85 & \multicolumn{2}{|c|}{$\mathrm{m} 4(\theta) \quad 0.15$} \\
\hline $\mathrm{m} 3\{\mathrm{G} 1\}$ & 0.85 & $\{\mathrm{G} 1\}$ & 0.723 & $\{\mathrm{G} 1\}$ & 0.13 \\
\hline $\mathrm{m} 3\{\mathrm{G} 1, \mathrm{G} 2\}$ & 0.105 & $\{\mathrm{G} 1\}$ & 0.089 & $\{\mathrm{G} 1, \mathrm{G} 2\}$ & 0.02 \\
\hline $\mathrm{m} 3(\theta)$ & 0.045 & $\{\mathrm{G} 1\}$ & 0.038 & $(\theta)$ & 0.007 \\
\hline
\end{tabular}

$\mathrm{m} 5\{\mathrm{G} 1\}=\frac{0.723+0.13+0.089+0.038}{1-0}=0,978$

$\mathrm{m} 5\{\mathrm{G} 1, \mathrm{G} 2\}=\frac{0,016}{1-0} \quad=0,016$

$\mathrm{m} 5(\theta) \quad=\frac{0,007}{1-0} \quad=0,007$

Nilai keyakinan paling kuat adalah terhadap gangguan disleksia (A) yaitu sebesar 0.978 yang di dapatkan dari tiga perilaku yaitu $\mathrm{P} 1, \mathrm{P} 2$ dan $\mathrm{P} 3$.

\section{Perilaku 4 : Lamban saat didikte atau menyalin tulisan}

Kemudian apabila diketahui adanya perilaku baru, yaitu lamban saat didikte atau menyalin tulisan (P4) yang merupakan analisa dari gangguan disleksia (A) dan disgrafia (B) :

$\mathrm{m} 6(\mathrm{P} 4)=0.75$

$\mathrm{m} 6\{\theta\}=1-\mathrm{m} 6(\mathrm{P} 3)$

$$
=1-0.75=0.30
$$

Jika diilustrasikan dalam tabel :

Tabel 8 Ilustrasi Nilai Keyakinan Empat Gejala

\begin{tabular}{|c|cc|cc|}
\hline & $\operatorname{m6}\{\mathrm{A}, \mathrm{B}\}$ & 0.75 & \multicolumn{2}{|c|}{$\operatorname{m6}(\theta) 0.25$} \\
\hline $\operatorname{m5}\{\mathrm{A}\}$ & $\{\mathrm{A}\}$ & 0.733 & $\{\mathrm{~A}\}$ & 0.244 \\
\hline
\end{tabular}




\begin{tabular}{|c|cc|cc|}
\hline $\mathrm{m} 5\{\mathrm{~A}, \mathrm{~B}\}$ & $\{\mathrm{A}, \mathrm{B}\}$ & 0.012 & $\{\mathrm{~A}, \mathrm{~B}\}$ & 0.004 \\
\hline $\mathrm{m} 5(\theta)$ & $\{\mathrm{A}, \mathrm{B}\}$ & 0.005 & $(\theta)$ & 0.002 \\
\hline
\end{tabular}

Dari perkalian di atas maka harus di hitung nilai irisan yang sama

$\mathrm{m} 7\{\mathrm{~A}\}=\frac{0.733+0.244}{1-0} \quad=0,978$

$\mathrm{m} 7\{\mathrm{~A}, \mathrm{~B}\} \quad=\frac{0.012+0.004}{1-0}=0,021$

$\mathrm{m} 7(\theta)$

$$
=\frac{0,002}{1-0}=0,002
$$

Nilai keyakinan paling kuat adalah terhadap gangguan disleksia (A) yaitu sebesar 0.978 yang di dapatkan dari tiga perilaku yaitu P1, P2, P3 dan P4.

\section{Perilaku 5 : Sulit Berkonsentrasi (P8)}

Kemudian apabila diketahui adanya perilaku baru, yaitu sulit berkonsentrasi (P8) yang merupakan analisa dari gangguan disgrafia (B) dan Diskalkulia (C) :

$\mathrm{m} 8(\mathrm{P} 5)=0.75$

$\mathrm{m} 8\{\theta\}=1-\mathrm{m} 6(\mathrm{P} 3)$

$$
=1-0.75=0.30
$$

Jika diilustrasikan dalam tabel

Tabel 9 Ilustrasi Nilai Keyakinan Lima Gejala

\begin{tabular}{|cc|cc|cc|}
\hline & $\mathrm{m} 8\{\mathrm{~B}, \mathrm{C}\}$ & 0.75 & \multicolumn{2}{|c|}{$\mathrm{m} 8(\theta)$} & 0.25 \\
\hline $\mathrm{m} 7\{\mathrm{~A}\}$ & 0.978 & $\{\theta\}$ & 0.733 & $\{\mathrm{G} 1\}$ & 0.244 \\
\hline $\mathrm{m} 7\{\mathrm{~A}, \mathrm{~B}\}$ & 0.021 & $\{\mathrm{~B}\}$ & 0.016 & $\{\mathrm{~A}, \mathrm{~B}\}$ & 0.005 \\
\hline $\mathrm{m} 7(\theta)$ & 0.002 & $\{\mathrm{~B}, \mathrm{C}\}$ & 0.001 & $(\theta)$ & 0.00032 \\
\hline
\end{tabular}

$$
\begin{array}{lll}
\mathrm{m} 9\{\mathrm{~A}\}=\frac{0.244}{1-0.733} \quad=0,916 & \\
\mathrm{~m} 9\{\mathrm{~B}\}=\frac{0.016}{1-0.733} \quad=\frac{0.005}{1-0.733} & =0,019 \\
\mathrm{~m} 9\{\mathrm{~A}, \mathrm{~B}\} \quad=\frac{0.001}{1-0.733} & =0,005 \\
\mathrm{~m} 9\{\mathrm{~B}, \mathrm{C}\} \quad=\frac{0.00032}{1-0.733} & =0,00119
\end{array}
$$

Nilai keyakinan paling kuat adalah terhadap gangguan disleksia (A) yaitu sebesar 0.916 yang di dapatkan dari tiga perilaku yaitu $\mathrm{P} 1, \mathrm{P} 2, \mathrm{P} 3, \mathrm{P} 4$ dan $\mathrm{P} 5$.

Berikut adalah presentase hasil analisa jenis gangguan berdasarkan perilaku yang sudah dipilih oleh pasien

Tabel 10 Hasil Analisa Perilaku Aris

\begin{tabular}{|c|c|c|c|}
\hline No & $\begin{array}{c}\text { Kode } \\
\text { Gangguan }\end{array}$ & Jenis Gangguan & Nilai Presentase DS \\
\hline 1 & A & $\begin{array}{c}\text { Disleksia } \\
\text { (Ganguan Membaca) }\end{array}$ & $91.5691 \%$ \\
\hline
\end{tabular}


Form tampilan data pasien merupakan form yang digunakan untuk menginput data pasien yang akan melakukan analisa terhadap gangguan belajar akademik. Dibawah ini merupakan tampilan data pasien:

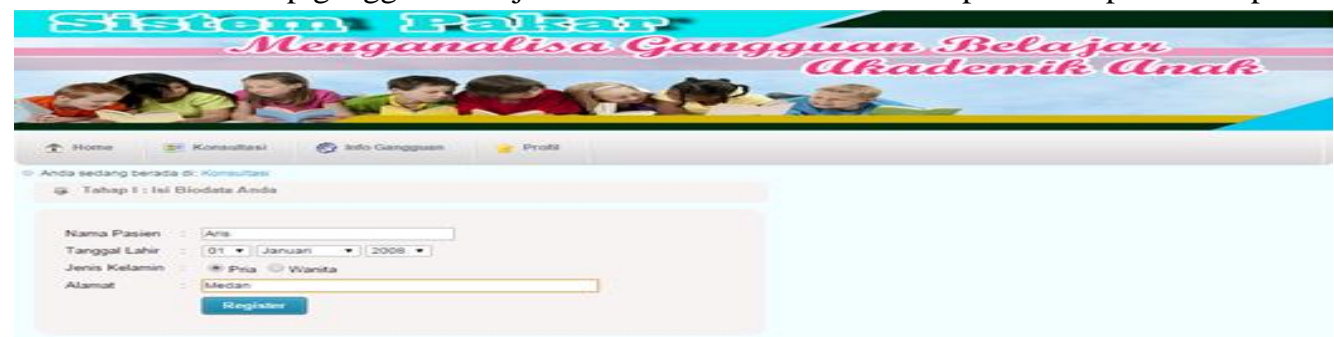

Gambar 1 Tampilan Data Pengunjung

Form data perilaku merupakan form yang digunakan untuk memilih dataperilaku yang terjadi anak yang akan di analisa, dibawah ini merupakan tampilan daftar perilaku gangguan belajar akademik sebagai berikut :

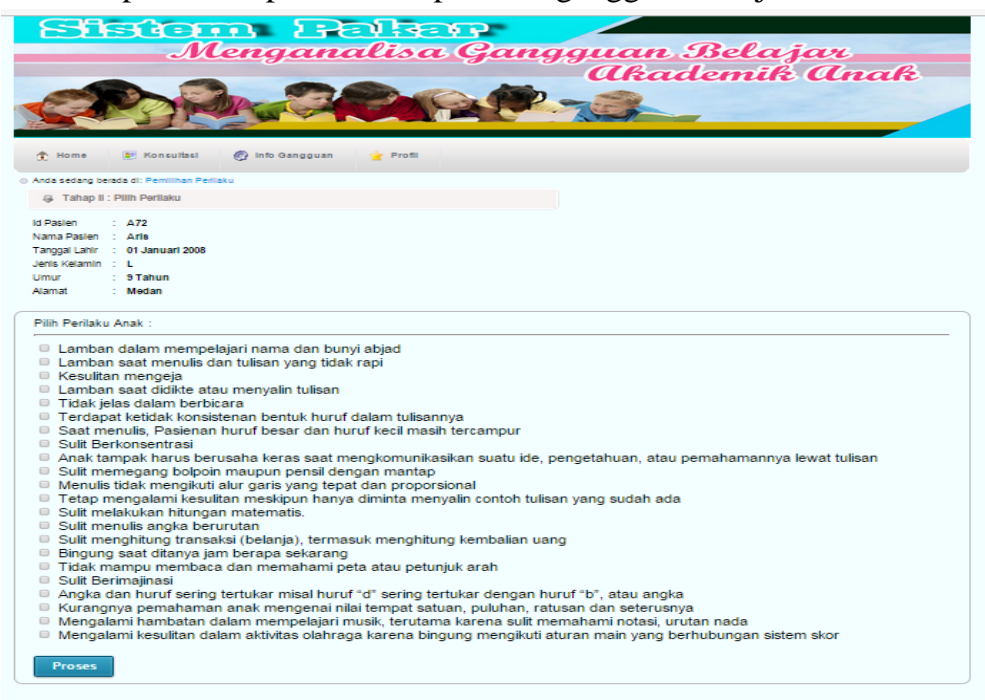

Gambar 2 Tampilan Daftar Perilaku

Form tampilan info gangguan merupakan tampilan yang menjelaskan pengertian dan penyebab gangguan belajar akademik yang terjadi pada anak. Berikut ini merupakan tampilan info gangguan :

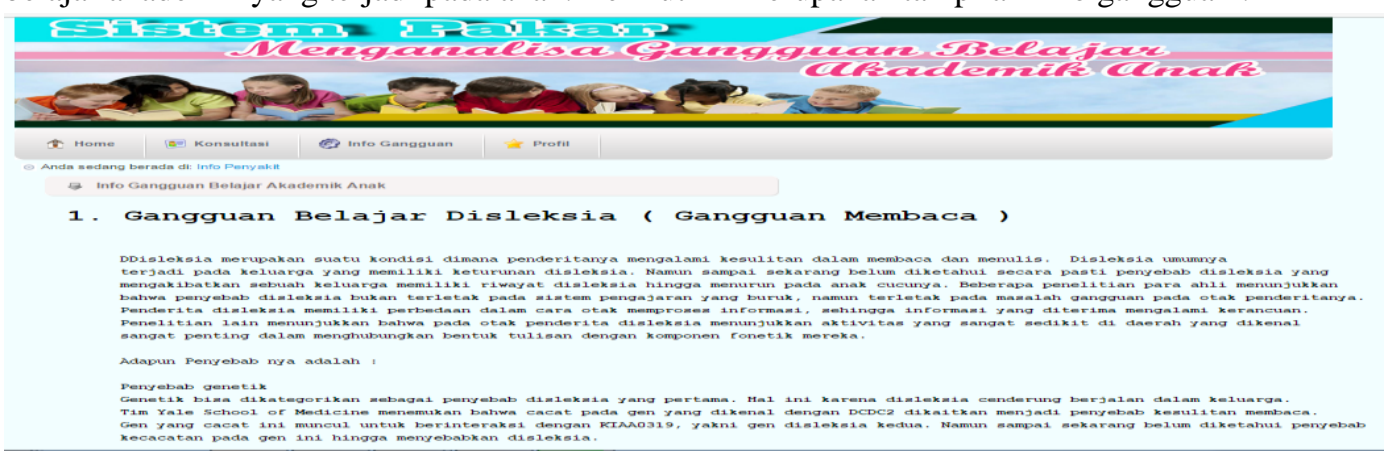

Gambar 3 Tampilan Info Gangguan

\section{KESIMPULAN}

Adapun yang menjadi kesimpulan dari sistem pakar untuk menganalisa gangguan belajar akademik pada anak dengan menggunakan metode Dempster Shafer adalah :

1 Menganalisa gangguan belajar akademik pada anak dengan metode dempster merupakan solusi yang baik dalam konsultasi dan memecahkan persoalan.

2 Merancang sistem dengan menggunakan metode dempster untuk menganalisa gangguan belajar akademik yang terjadi pada anak. 
3 Menguji sistem menganalisa gangguan belajar akademik yang terjadi pada anak

\section{DAFTAR PUSTAKA}

T.Sutojo/Edi.M/Vincent.S.2010.Kecerdasan Buatan.Semarang;Andi

Zulfian Azmi.2017.Pengantar Sistem Pakar Dan Metode.Jakarta: Mitra Wacana Media

Ignizio, J. P. 1991. Introduction To Expert Systems : The Development and Implementation of Rule-Based

Expert Systems. McGraw-Hill, Inc., New York. Kusrini. 2006. Sistem Pakar Teori dan Aplikasi.

Penerbit Andi, Yokyakarta.

Development of Fuzzy Expert System for the Neo Phropathy Control assessment

in Patient with 2 Diabetes Melitus. Di temu kenali Homepage:www.elsevier.com /licate/eswa.

Ditemui kenali pada tanggal 16 Juni 2017 dari www.kamus bahasaindonesia.org 